\title{
Introducing Associate Editors
}

Nutrition\& Metabolism

\section{Associate Editor Anja Kroke}

We would like to introduce our new associate editor.

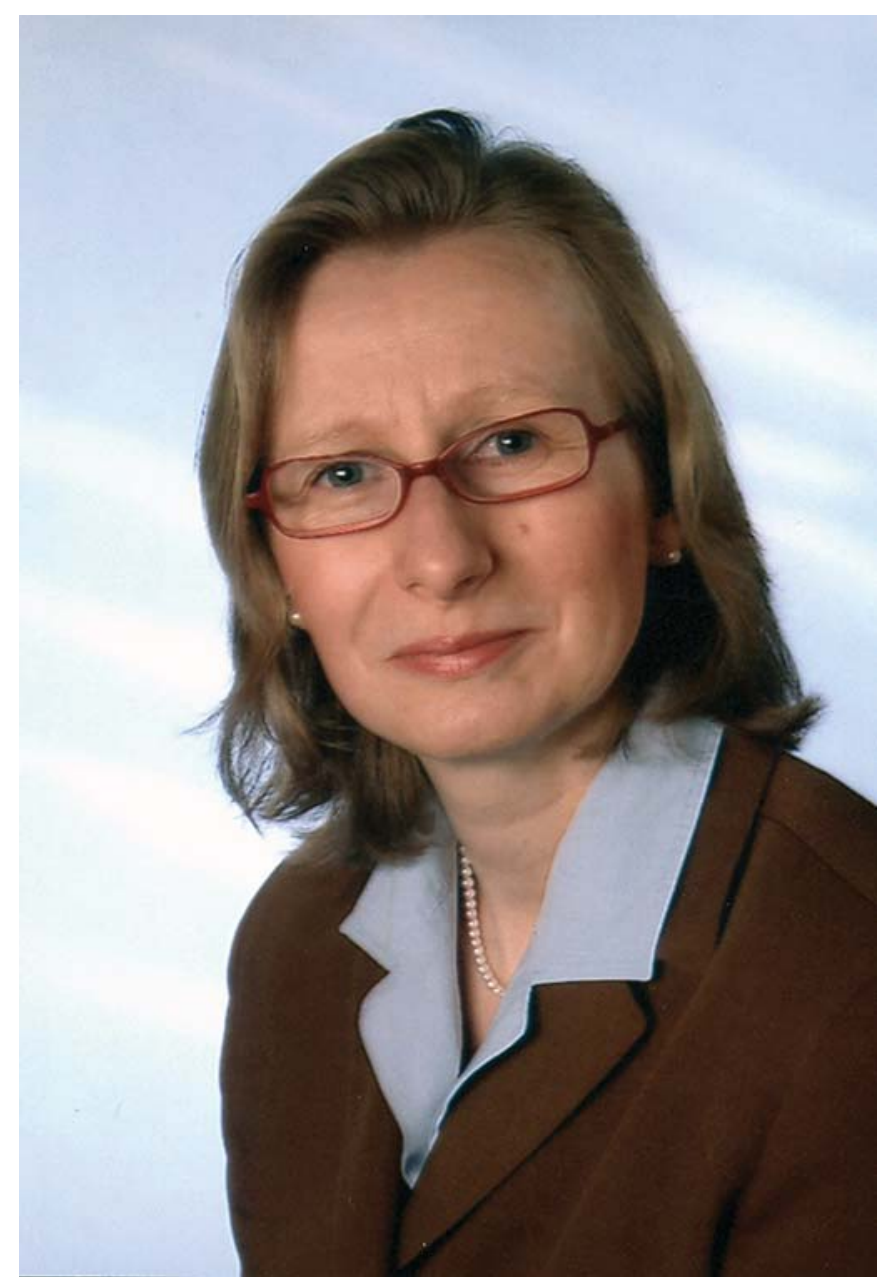

\section{Anja Kroke}

Hochschule Fulda

FB Oecotrophologie

\section{Curriculum Vitae}

1983-1991

Study of Medicine at Hannover Medical School and Free University Berlin (FU Berlin)

1992-1993

Research Assistant at the Federal Health Office, Berlin, Germany 1992

Doctoral Degree in Epidemiology, Free University Berlin (FU Berlin), Germany 1993-1994

Master's Studies of 'Public Health' at University of North Carolina at Chapel Hill, USA 1994

Master Degree in Public Health, University of North Carolina at Chapel Hill, USA 1994-2002

Research Assistant at the German Institute of Human Nutrition

1995-2001

Part-time Lecturer at the University of Potsdam and the Charité Berlin 2002

PhD Qualification at the Department of Epidemiology at the Humboldt University - Charité Berlin 2002-2006

Assistant Scientific Director at the Research Institute of Child Nutrition, Dortmund, Germany 2006-Present

Full Professor at the University of Applied Sciences Fulda, Germany

\section{KARGER}

(C) 2017 S. Karger AG, Basel

E-Mail karger@karger.com

www.karger.com/anm
Prof. Dr. Anja Kroke

Hochschule Fulda, FB Oecotrophologie

Leipziger Str. 123

DE-36037 Fulda (Germany)

E-Mail anja.kroke@he.hs-fulda.de 